\title{
Recommendations for Antibacterial Prophylaxis in Endourological Procedures
}

\author{
Doo Yong Chung, Joo Yong Lee ${ }^{1}$ \\ Department of Urology, Inha University School of Medicine, Incheon, ${ }^{1}$ Department of Urology, Severance Hospital, Urological Science \\ Institute, Yonsei University College of Medicine, Seoul, Korea
}

This review discusses the evidence and newly identified findings of antibiotic prophylaxis in endourological procedures based on recently published studies. Endoscopic procedures and surgeries are performed widely to treat a variety of urologic diseases. The panel of European Association of Urology (EAU) guidelines on UTIs decided not to make recommendations for specific agents for particular procedures because there are considerable variations in Europe and worldwide regarding bacterial pathogens, their susceptibility, and the availability of antibiotic agents in 2018. In the EAU guidelines, antimicrobial prophylactic therapies cannot decrease the rate of symptomatic UTI in several procedures, including cystoscopy and extracorporeal shock wave lithotripsy. Perioperative antibiotic prophylaxis can be helpful in all patients undergoing endourological treatment, including ureteroscopic surgery and percutaneous nephrolithotomy. Because the urological practice is a part of the surgery, most urological treatment can be performed mainly by surgery. The prevention of surgical infections in each surgical field is a critical issue, but the evidence and number of guidelines are limited.

Keywords: Urinary tract infections; Urology; Endoscopy; Urinary calculi; Cystoscopy

Copyright (c) 2019, Korean Association of Urogenital Tract Infection and Inflammation. All rights reserved. (c) (1) (\$) This is an open access article distributed under the terms of the Creative Commons Attribution (C) (1) (5) Non-Commercial License (http://creativecommons.org/licenses/by-nc/4.0) which permits unrestricted non-commercial use, distribution, and reproduction in any medium, provided the original work is properly cited.
Received: 11 February, 2019

Revised: 17 April, 2019

Accepted: 18 April, 2019

\author{
Correspondence to: Joo Yong Lee \\ (iD) https://orcid.org/0000-0002-3470-1767 \\ Department of Urology, Severance Hospital, \\ Urological Science Institute, Yonsei University \\ College of Medicine, 50-1 Yonsei-ro, Seodaemun- \\ gu, Seoul 03722, Korea \\ Tel: +82-2-2228-2320, Fax: +82-2-312-2538 \\ E-mail: joouro@yuhs.ac
}

\section{INTRODUCTION}

Endoscopic procedures and surgeries are performed widely to treat a range of urologic diseases. Endoscopy is usually considered to be a minimally invasive surgical approach because it allows surgical treatment without a parietal incision, thereby avoiding the specific complications of surgical wounds and reducing the level of postoperative pain [1]. Endoscopic procedures have evolved rapidly in recent years because of the number of technical innovations [2] and are considered first-line options for the treatment of benign prostatic hyperplasia (BPH), stone disease, and non-muscle-invasive urothelial cancer [3-5].
Antibiotic prophylaxis is an accepted and widely practiced feature of recent surgery [6]. The prevention and control of infection is a priority in healthcare worldwide, but the emergence of antibiotic resistance is a global phenomenon. Therefore, the rational use of antibiotics is essential in various surgical procedures, particularly endourologic surgeries. Ureteroscopic lithotripsy (URSL) and percutaneous nephrolithotomy (PCNL) are common endourologic surgeries performed to treat renal stones [7]. Endourologic surgery carries the risk of postoperative infection, affecting up to $1.8 \%$ of patients in URSL [8], and 35\% in PCNL [9]. In previous studies, urosepsis can occur regardless of the use of pre-procedural antibiotics [10]. In a transurethral 
resection of the prostate (TURP) for $\mathrm{BPH}$, the postoperative incidence of postoperative urinary tract infection (UTI) has been reported to be between $6 \%$ and $60 \%$ [11]. This review discusses the evidence and newly identified findings of antibiotic prophylaxis in endourological procedures based on recently published studies.

\section{EAU GUIDELINES ON UTI AND UROLI- THIASIS, AUA GUIDELINES AND JUA GUIDE- LINES}

The European Association of Urology (EAU) guidelines on urological infections guidelines panel compiled these clinical guidelines to provide medical professionals with evidence- based information and recommendations for the prevention and treatment of UTIs; these guidelines are updated every year. In the EAU guidelines on UTIs, the clinical guidelines present the best evidence available to the experts. On the other hand, following the guideline recommendations will not necessarily result in the best outcome. Regarding antibiotic prophylaxis, the EAU guidelines on UTIs suggested two general principles, including non-antibiotic measures for asepsis and the choice of agents. In non- antibiotic treatment, urologists and their hospital should consider and monitor aseptic environments to reduce the risk of infection within patients (microbiome) and external (nosocomial/healthcare associated) pathogens outside the hospital. This should include proper cleaning and sterilization methods, frequent and thorough cleaning of operating theaters and recovery areas, and thorough disinfection of contamination. The surgical team should prepare for surgery with effective hand washing, proper protective clothing, and sterile maintenance [12]. Regarding the choice of agents, the urologists must have knowledge of each type of procedure, antibiotic susceptibility profile, and local pathogen prevalence for virulence to establish written regional guidelines. The EAU guidelines panel on UTI decided not to make recommendations for specific agents for specific procedures regarding the susceptibility and availability of bacterial pathogens and antimicrobial agents because of the significant differences between Europe and the rest of the world in 2018. In the EAU guidelines on urolithiasis, the panels suggested that drainage should be performed for several days in patients who had clinically significant infections and obstructions before performing stone surgery, and a urine culture or microscopy should be performed prior to surgery [4].

In the American Urological Association (AUA) guidelines on the surgical management of stones published in 2016, clinicians are required to perform urine analysis before the interventional treatment $[13,14]$. A urine culture should be obtained in patients with clinical or laboratory signs of infection. On the other hand, the AUA guideline panels have not published recommendations on UTIs except for acute uncomplicated cystitis and pyelonephritis, and catheter-associated UTI $[15,16]$.

The Japanese Urological Association (JUA) published their guidelines on the prevention of perioperative infections in the urological field, including open, laparoscopic and endoscopic surgeries, and treatment of postoperative infections [17]. The JUA guidelines suggested that the several guidelines of urology were different from those of general surgery, because urological surgeries include many endourological procedures that can result in urine exposure in the surgical field.

\section{CYSTOSCOPY}

In the EAU guidelines for UTIs, the panel suggested that antibiotic prophylaxis offered no benefit in the proportion of urinary infections with symptoms after cystoscopy. Two systematic reviews and meta-analyses have been published $[18,19]$. The meta-analysis study regarding antibiotic prophylaxis for cystoscopy reported by Garcia-Perdomo et al. [19] included seven randomized controlled trial (RCT)s with a total of 3,038 participants. The outcome of symptomatic UTI was measured by five trials of moderate quality overall and meta-analysis revealed a benefit in the use of antibiotic prophylaxis. Subgroup analysis, however, showed that only two studies were classified as having a low risk of bias: Cam et al. [20] and Garcia-Perdomo et al. [21], who both reported no significant differences. This study found moderate evidence against recommending antimicrobial prophylactic therapy to prevent UTI and asymptomatic bacteriuria in patients undergoing cystoscopy with sterile urine. The other meta-analysis study for flexible cystoscopy reported by Carey et al. [18] included seven RCTs with a total of 5,107 participants. Antibiotic prophylaxis did reduce the number of cases of symptomatic (odds ratio [OR], 0.34; 95\% confidence interval [CI], 0.25 to 0.47 ) 
and asymptomatic bacteriuria (OR, 0.4; 95\% CI, 0.29 to $0.54)$ but the number required for treatment were high. Therefore, the authors could not advocate the use of antibiotic prophylaxis for routine flexible cystoscopy procedures. The absolute risk of post-procedural UTI in well-resourced countries is low. In addition, a large number of procedures are performed. The use of prophylactic antibiotics carries the high risk of contributing to increasing antimicrobial resistance. Therefore, the EAU guidelines strongly recommend against the use of antibiotic prophylaxis in patients undergoing flexible or rigid cystoscopy. In the JUA guidelines [17], antibiotic prophylaxis also is not necessary for patients without the risk factors. On the other hand, if bacteriuria or UTI findings are detected prior to cystoscopy, an attempt should be made to avoid the use of antimicrobial agents that are expected to be effective. In addition, they recommended antibiotic prophylaxis for patients with risk factors, such as the presence of a urethral catheter or ureteral stent, intermittent self-catheterization, urinary retention, and a recent history of UTIs if there is no detection of bacteriuria or UTI before cystoscopy [22].

Two guidelines recommend routine antibiotic prophylaxis be avoided in patients without the risk factors who are undergoing flexible or rigid cystoscopy. Nevertheless, it is recommended to check for bacteriuria before the procedure, and prophylactic antibiotics should be considered in patients with the risk factors.

\section{TRANSURETHRAL RESECTION OF PROSTATE}

The EAU guidelines on UTIs recommended that single dose antibiotic prophylaxis can reduce the rate of clinical UTI following TURP. A systematic review of prophylactic antibiotics in TURP is well documented. The most recent systematic review reported by Mrkobrada et al. [23] included a total of 28 trials (4,694 patients) comparing antibiotics versus the placebo. The incidence of infection-related adverse events was higher in patients who underwent TURP without prophylactic antibiotics. Bacteriuria, bacteremia, and fever were noted in $23.4 \%, 4.0 \%$, and $26.9 \%$ of patients, respectively. Antibiotics reduced the rates of bacteriuria (RR, 0.34; 95\% CI, 0.30 to 0.40), bacteremia (RR, 0.84; 95\% CI, 0.71 to 0.99 ), and fever (RR, 0.25; 95\% CI 0.11 to 0.56) significantly. No side effects associated with antibiotic prophylaxis were recorded in those studies. Berry and Barratt [24] performed a meta-analysis of 32 RCTs (4,260 patients), and confirmed that the use prophylactic antibiotics prior to TURP reduced significantly the incidence of both bacteriuria (RR, $0.65 ; 95 \% \mathrm{CI}, 0.56$ to 0.73 ) and clinical septicemia (RR, $0.77 ; 95 \% \mathrm{CI}, 0.55$ to 0.88 ). The other meta-analysis came to the same conclusion [25]. JUA [17] and the Canadian Urological Association (CUA) [23] guidelines also recommended that prophylactic antibiotics be considered in patients who undergo TURP. All guidelines recommend the use of antibiotic prophylaxis in men undergoing TURP because of the reduced risk of febrile UTI after TURP procedures. In addition, it is advisable to treat asymptomatic bacteriuria before performing other urological procedures that are likely to cause mucosal bleeding. In the guidelines for the Antibiotics use in urinary tract infection published by the Korea Centers for Disease Control \& Prevention in 2018, asymptomatic bacteriuria should be screened and treated before any procedures that could involve mucosal bleeding, including TURP.

\section{TRANSURETHRAL RESECTION OF BLAD- DER TUMOR (TURBT)}

EAU guidelines on UTIs recommended the use of antimicrobial prophylactic therapy for patients who undergo TURBT and have a high risk of post-operative sepsis. Optionally, low-risk patients can be considered as not requiring prophylactic antibiotics [26]. The incidence of postoperative UTIs in TURBT ranged from 10\% to $40 \%$ $[27,28]$. A literature review found one systematic review that included two trials with a total of 152 participants [29]. The two reviewed trials found no difference in the rate of bacteriuria and neither had clinical UTI events, or reported clinical UTI.

The studies by Delavierre et al. [30] and MacDermott et al. [31] are relatively outdated and included a small number of patients. Both studies reported no significant decrease in the incidence of bacteriuria after TURBT using antibiotic prophylaxis $(24.1 \%$ in the placebo vs. $9.4 \%$ in antimicrobial prophylaxis; $17 \%$ in placebo vs. $4.5 \%$ in antimicrobial prophylaxis). Delavierre et al. [30] reported that both groups had no incidence of symptomatic UTI. On the other hand, both studies did not perform further analysis according to the presence of risk factors for post-operative UTI, including the tumor size and preoperative urinary tract 
catheterization. Appell et al. [32] reported that occult bacterial colonization to the bladder tumor caused postoperative UTI, even if the preoperative urine was sterile, and the incidence of UTIs after TURBT was higher than that after TURP. Therefore, the JUA guidelines [17] recommend the use of prophylactic antibiotics in patients undergoing TURBT based on Japanese circumstances. Overall, the use of antibiotic prophylaxis to reduce infectious complications may be considered in high-risk patients undergoing TURBT.

\section{EXTRACORPOREAL SHOCK WAVE LITHO- TRIPSY (ESWL)}

ESWL is now a common procedure for renal and ureter stones less than 1 or $2 \mathrm{~cm}$ in size, breaking the calculi without making a wound and invasiveness [33]. The incidence of symptomatic UTI after ESWL was quite low in $3 \%(0 \%$ to $10 \%)$ of patients without preoperative bacteriuria [17]. The EAU guidelines on UTIs recommended that prophylactic antibiotics be avoided in patients undergoing ESWL because of the lack of benefit in reducing infectious complications and the possible risk of increasing bacterial resistance and the side effects of antibiotics. Two systematic reviews and meta-analyses for the use of prophylactic antibiotics in patients without bacteriuria undergoing ESWL were identified. The study published by Lu et al. [34], included nine RCTs with a total of 1,364 patients. Antibiotic prophylaxis could not improve the symptoms, and decreased neither the post-ESWL fever and bacteriuria, nor the incidence of UTI after ESWL. Mrkobrada et al. [23] included eight randomized studies with a total of 940 participants. This study also found no evidence that prophylactic antibiotics for ESWL help reduce infections [23]. Hsieh et al. [35] reported RCT with 274 patients. The results showed no benefit of using a single dose of levofloxacin (500 mg) for preventing pyuria, bacteriuria, and febrile UTI after ESWL [35]. In contrast, there were several factors related to bacteriuria. Patients with large infected stones $(>2 \mathrm{~cm})$ had a high risk of febrile UTI following ESWL [36]. A previous study reported that patients with stones greater than $3 \mathrm{~cm}$ in diameter have a significantly higher rate of bacteriuria than those with renal stones 0.4 to $3 \mathrm{~cm}$ in diameter (20\% vs. $10 \%$ ) [37]. In addition, struvite stones were found to be associated more frequently with bacteriuria after ESWL than other types of stones (17.3\% vs. 2.1\%) [38]. Honey et al. [39] reported a prospective case-series of 526 shockwave lithotripsy patients. In this study, among the 389 patients included, only eight high risk cases received selective antimicrobial prophylaxis. They documented very low rates of UTI (0.3\%) and asymptomatic bacteriuria (2.8\%). According to this result, they suggested that antibiotic prophylaxis for ESWL provides no benefit except for those at a high risk of infection. The CUA guidelines and JUA guidelines also recommend that prophylactic antibiotics is unnecessary for patients who had no pre-ESWL bacteriuria because of the low incidence of post-ESWL symptomatic UTIs or bacteremia following ESWL. These guidelines, however, recommend that antibiotic prophylaxis be considered for those with the risk factors of developing pyelonephritis after ESWL, such as preoperative bacteriuria, repeated ESWL, infected stones, and stones with a size of $\geq 2 \mathrm{~cm}$.

\section{URETEROSCOPY}

In the EAU guidelines on UTI, the panels suggested that antimicrobial prophylactic therapy can reduce the rate of symptomatic UTI following ureteroscopic surgery. In a systematic review in 2008 [29], two randomized studies with a total of 233 participants reported that prophylactic antibiotic therapy reduced the risk of bacteriuria but not clinical UTI $[8,40]$. Those two RCTs on UTI following ureteroscopy provided low grade evidence because they were published in 1990 [40] and 2003 [8]. In 2015, Lo et al. [41] from Taiwan reported a systematic review and metaanalysis on the effectiveness of prophylactic antibiotics against post-URSL. In total, four trials enrolling 500 patients met the inclusion criteria and were subjected to metaanalysis. Prophylactic antibiotic therapy decreased significantly the incidence of postoperative pyuria (RR, 0.65; $95 \% \mathrm{CI}, 0.51$ to 0.82 ) and bacteriuria (RR, 0.26; $95 \% \mathrm{CI}$, 0.12 to $0.60 ; \mathrm{p}=0.001$ ). Patients who underwent prophylactic antibiotic therapy tended to have a lower febrile UTI rate, even though there was no significant difference. They concluded that antibiotic prophylaxis can decrease the incidence of pyuria and bacteriuria after ureteroscopy. On the other hand, they failed to prove that a single dose of prophylactic antibiotics can reduce the rate of UTI significantly because of the low incidence of postoperative febrile UTIs. The rate of bacteriuria was reduced using 
antibiotic prophylaxis. The EAU panel discussion considered that despite the low quality evidence suggesting no benefit in reducing the risk of clinical UTI, clinicians and patients would prefer to use prophylaxis to prevent kidney infection or sepsis. Ideally, this should be examined in a robustly designed clinical study.

In the EAU guidelines on urolithiasis, UTI should always be treated if stone surgery is planned [4]. In patients with a clinically significant infection and obstruction, preoperative drainage should be performed for several days before starting stone surgery. In addition, a urine culture or urinary microscopy should be performed before surgery [42]. To prevent infection following ureteroscopy and percutaneous stone surgery, however, there has been no clear-cut evidence until now [41].

In the JUA guidelines, postoperative UTIs occur easily and sometimes develop into febrile UTIs, because these obstructions are present or the procedure is invasive [17]. In particular, ureterorenoscopic observations of the upper urinary tract sometimes take a long time, resulting in invasiveness. The operation time and operative invasiveness depend on the individual. The operative invasiveness also depend on the type of ureterorenoscope (rigid or flexible, size, etc.). For these reasons, it is difficult to unify antimicrobial prophylaxis. Therefore, they recommended routine prophylaxis in the JUA guidelines based on Japanese circumstances. The CUA guidelines suggested that periprocedural antibiotics be considered in patients undergoing ureteroscopy and the choice of specific agent for prophylaxis should be based, in part, on the regional epidemiology of antibiotics resistance in potential uropathogens [23].

These guidelines recommended perioperative antibiotic prophylaxis in all patients undergoing endourological treatment.

\section{PERCUTANEOUS NEPHROLITHOTOMY}

In the EAU guidelines on urolithiasis, ESWL and retrograde intrarenal surgery are recommended as the first-line treatment for renal stones $<2 \mathrm{~cm}$ in length, and PCNL is recommended as a first-line treatment for renal stones $\geq 2 \mathrm{~cm}[7,43]$. The EAU guidelines on UTIs recommended that single dose antibiotic prophylaxis can reduce the rate of clinical urinary infection following PCNL. The CUA guidelines also recommended that peri-procedural antibiotics be considered in patients undergoing ureteroscopy and PCNL [23]. They suggested that the choice of a specific agent for prophylaxis should be based, in part, on the local epidemiology of drug resistance in potential uropathogens. Seyrek et al. [44] compared sulbactam-ampicillin and cefuroxime antibiotics for the prophylaxis of PCNL and determine the optimal regimen for prophylactic antibiotic maintenance to prevent systemic inflammatory response syndrome (SIRS). In their study, 198 patients, in whom PCNL had been performed, were randomized prospectively into two groups regarding the type of prophylactic antibiotics including sulbactam-ampicillin in group 1 and cefuroxime in group 2 . In the positive culture rates, there was no difference between the two groups. SIRS was observed in 13 (43.3\%) patients in group 1 and 17 patients (56.7\%) in group $2(\mathrm{p}=0.44)$. In the relationship between the duration of antibiotic maintenance and SIRS development, there was no difference between the two groups $(\mathrm{p}=0.95$ for group $1 ; \mathrm{p}=0.39$ for group 2$)$. Two patients had urosepsis after PCNL, and one patient died from septic shock. They concluded that sulbactam-ampicillin and cefuroxime antibiotics can be used safely for prophylaxis in patients undergoing PCNL and single dose administration would be sufficient. Tuzel et al. [45] compared two different protocols of antibiotic prophylaxis in PCNL. In their prospective study, 73 patients with preoperative sterile urine were divided into single-dose or short-course antibiotic prophylaxis groups. The patients in group $1(n=36)$ were given only a single dose of ceftriaxone during the induction of anesthesia, while group 2 ( $n=37)$ were given oral thirdgeneration cephalosporin after ceftriaxone until nephrostomy catheter withdrawal. Fever of $>38^{\circ} \mathrm{C} \quad(\mathrm{p}=0.52)$ developed in four (11.1\%) patients in group 1 and six (16.2\%) patients in group 2. Positive stone cultures developed in eight patients. Of those, three (8.3\%) were in the first group and five (13.5\%) were in the second group $(\mathrm{p}=0.47)$. The urine sent for culture on the nephrostomy catheter withdrawal day had positive results in three and two patients for groups 1 and 2, respectively $(\mathrm{p}=0.54)$. The authors suggested that both antibiotic prophylaxis methods were similar in terms of preventing septic complications and recommended a single-dose antibiotic prophylaxis protocol to patients undergoing PCNL.

In the EAU guidelines on urolithiasis, antibiotic prophylaxis decreased significantly the rate of post-operative fever 
Table 1. Recommendations according to the guidelines for antibiotic prophylaxis in endourological procedures

\begin{tabular}{|c|c|c|c|c|c|}
\hline \multirow[b]{2}{*}{ Procedure } & \multirow[b]{2}{*}{ Risk factor } & \multicolumn{4}{|c|}{ Guidelines } \\
\hline & & $\begin{array}{l}\text { European Association } \\
\text { of Urology }\end{array}$ & $\begin{array}{l}\text { American Urological } \\
\text { Association }\end{array}$ & $\begin{array}{l}\text { Japanese Urological } \\
\text { Association }\end{array}$ & $\begin{array}{c}\text { Canadian Urological } \\
\text { Association }\end{array}$ \\
\hline Cystoscopy & $\begin{array}{l}\text { Most patients } \\
\text { High risk patients (the presence of } \\
\text { a urethral catheter or ureteral } \\
\text { stent, intermittent } \\
\text { self-catheterization, urinary } \\
\text { retention, and recent history of } \\
\text { UTIs, etc.) }\end{array}$ & $\begin{array}{l}\text { Not recommended } \\
\text { Not mentioned }\end{array}$ & $\begin{array}{l}\text { Not recommended } \\
\text { Not mentioned }\end{array}$ & $\begin{array}{l}\text { Not recommended } \\
\text { Recommended }\end{array}$ & $\begin{array}{l}\text { Not recommended } \\
\text { Recommended }\end{array}$ \\
\hline TURP $P^{\text {a) }}$ & All patients & Recommended & Recommended & Recommended & Recommended \\
\hline TURBT $^{\text {a) }}$ & All patients & Weakly recommended & Recommended & Recommended & Not mentioned \\
\hline ESWL & $\begin{array}{l}\text { Most patients } \\
\text { High risk patients (preoperative } \\
\text { bacteriuria, repeated ESWL, } \\
\text { infected stones, and stones with } \\
\text { a size of } \geq 2 \mathrm{~cm} \text {, etc.) }\end{array}$ & $\begin{array}{l}\text { Not recommended } \\
\text { Not mentioned }\end{array}$ & $\begin{array}{l}\text { Not recommended } \\
\text { Recommended }\end{array}$ & $\begin{array}{l}\text { Not recommended } \\
\text { Recommended }\end{array}$ & $\begin{array}{l}\text { Not recommended } \\
\text { Recommended }\end{array}$ \\
\hline Ureteroscopy & All patients & Recommended & Recommended & Recommended & Recommended \\
\hline $\begin{array}{l}\text { Percutaneous } \\
\text { nephrolithotomy }\end{array}$ & All patients & Recommended & Recommended & Recommended & Recommended \\
\hline
\end{tabular}

and other complications in patients with negative baseline urine culture [4]. In addition, EAU guidelines recommended that single dose administration is sufficient and perioperative antibiotic prophylaxis can be performed on all patients undergoing endourological treatment with a high strength rating in the guidelines recommendation.

\section{CONCLUSIONS}

Most urological practice consists of surgical procedures because the field of urology is a division of surgery. In particular, endourologic procedures have been developed with an improvement of endoscope and instrumentation. Although the prevention of perioperative infections in each surgical field is a very important issue, the evidence and number of guidelines are limited. In addition, quinolone resistance has been reported to be higher in Korea than in other countries. Furthermore, the resistance rate of domestic pathogens against trimethoprim-sulfamethoxazole antibiotics, which is recommended as a primary antibiotic for urinary tract infections in US or Europe, is also high. This is why it is difficult to apply other national guidelines directly to Korea. Most reported studies have used first or second generation cephalosporin or quinolone series as antibiotic prophylaxis. Although no prophylactic anti- biotics have been established for Korea, this paper recommends that the first or second generation cephalosporin be used as antibiotic prophylaxis. Therefore, guidelines should be developed based on Korean circumstances (Table $1)$.

\section{CONFLICT OF INTEREST}

No potential conflict of interest relevant to this article was reported.

\section{AUTHOR CONTRIBUTIONS}

D.Y.C. participated in data collection. D.Y.C. and J.Y.L. wrote the manuscript. J.Y.L. participated in the study design and coordination and helped to draft the manuscript. D.Y.C. and J.Y.L. read and approved the final manuscript.

\section{ORCID}

Doo Yong Chung, https://orcid.org/0000-0001-8614-5742 Joo Yong Lee, https://orcid.org/0000-0002-3470-1767 


\section{REFERENCES}

1. Cornu JN, Herrmann T, Traxer O, Matlaga B. Prevention and management following complications from endourology procedures. Eur Urol Focus 2016;2:49-59.

2. Herrmann TR, Liatsikos EN, Nagele U, Traxer O, Merseburger AS; EAU Guidelines Panel on Lasers, Technologies. EAU guidelines on laser technologies. Eur Urol 2012;61:783-95.

3. Oelke M, Bachmann A, Descazeaud A, Emberton M, Gravas S, Michel MC, et al.; European Association of Urology. EAU guidelines on the treatment and follow-up of non-neurogenic male lower urinary tract symptoms including benign prostatic obstruction. Eur Urol 2013;64:118-40.

4. Turk C, Petrik A, Sarica K, Seitz C, Skolarikos A, Straub M, et al. EAU guidelines on interventional treatment for urolithiasis. Eur Urol 2016;69:475-82.

5. Babjuk M, Bohle A, Burger M, Capoun O, Cohen D, Comperat $E M$, et al. EAU guidelines on non-muscle-invasive urothelial carcinoma of the bladder: update 2016. Eur Urol 2017;71:44761.

6. Dasgupta R, Grabe M. Preoperative antibiotics before endourologic surgery: current recommendations. J Endourol 2009; 23:1567-70.

7. Jung HD, Kim JC, Ahn HK, Kwon JH, Han K, Han WK, et al. Real-time simultaneous endoscopic combined intrarenal surgery with intermediate-supine position: washout mechanism and transport technique. Investig Clin Urol 2018;59:34854.

8. Knopf HJ, Graff HJ, Schulze H. Perioperative antibiotic prophylaxis in ureteroscopic stone removal. Eur Urol 2003;44: 115-8.

9. Draga RO, Kok ET, Sorel MR, Bosch RJ, Lock TM. Percutaneous nephrolithotomy: factors associated with fever after the first postoperative day and systemic inflammatory response syndrome. J Endourol 2009;23:921-7.

10. Eswara JR, Shariftabrizi A, Sacco D. Positive stone culture is associated with a higher rate of sepsis after endourological procedures. Urolithiasis 2013;41:411-4.

11. Lawson KA, Rudzinski JK, Vicas I, Carlson KV. Assessment of antibiotic prophylaxis prescribing patterns for TURP: a need for Canadian guidelines? Can Urol Assoc J 2013; 7:E530-6.

12. Tanner J, Dumville JC, Norman G, Fortnam M. Surgical hand antisepsis to reduce surgical site infection. Cochrane Database Syst Rev 2016;(1):CD004288.

13. Assimos D, Krambeck A, Miller NL, Monga M, Murad MH, Nelson $\mathrm{CP}$, et al. Surgical management of stones: American Urological Association/Endourological Society guideline, part I. J Urol 2016;196:1153-60.

14. Assimos D, Krambeck A, Miller NL, Monga M, Murad MH, Nelson CP, et al. Surgical management of stones: American Urological Association/Endourological Society guideline, part II. J Urol 2016;196:1161-9.
15. Gupta K, Hooton TM, Naber KG, Wullt B, Colgan R, Miller LG, et al. International clinical practice guidelines for the treatment of acute uncomplicated cystitis and pyelonephritis in women: a 2010 update by the Infectious Diseases Society of America and the European Society for Microbiology and Infectious Diseases. Clin Infect Dis 2011;52:e103-20.

16. Hooton TM, Bradley SF, Cardenas DD, Colgan R, Geerlings SE, Rice JC, et al.; Infectious Diseases Society of America. Diagnosis, prevention, and treatment of catheter-associated urinary tract infection in adults: 2009 international clinical practice guidelines from the Infectious Diseases Society of America. Clin Infect Dis 2010;50:625-63.

17. Matsumoto T, Kiyota H, Matsukawa M, Yasuda M, Arakawa S, Monden K; Japanese Society of UTI Cooperative Study Group (Chairman; Tetsuro Matsumoto). Japanese guidelines for prevention of perioperative infections in urological field. Int J Urol 2007;14:890-909.

18. Carey MM, Zreik A, Fenn NJ, Chlosta PL, Aboumarzouk OM. Should we use antibiotic prophylaxis for flexible cystoscopy? A systematic review and meta-analysis. Urol Int 2015;95:24959.

19. Garcia-Perdomo HA, Jimenez-Mejias E, Lopez-Ramos H. Efficacy of antibiotic prophylaxis in cystoscopy to prevent urinary tract infection: a systematic review and meta-analysis. Int Braz J Urol 2015;41:412-24; discussion 424.

20. Cam K, Kayikci A, Erol A. Prospective evaluation of the efficacy of antibiotic prophylaxis before cystoscopy. Indian J Urol 2009; 25:203-6.

21. Garcia-Perdomo HA, Lopez H, Carbonell J, Castillo D, Catano $J G$, Seron P. Efficacy of antibiotic prophylaxis in patients undergoing cystoscopy: a randomized clinical trial. World J Urol 2013;31:1433-9.

22. Rane A, Cahill D, Saleemi A, Montgomery B, Palfrey E. The issue of prophylactic antibiotics prior to flexible cystoscopy. Eur Urol 2001;39:212-4.

23. Mrkobrada M, Ying I, Mokrycke S, Dresser G, Elsayed S, Bathini $\mathrm{V}$, et al. CUA guidelines on antibiotic prophylaxis for urologic procedures. Can Urol Assoc J 2015;9:13-22.

24. Berry A, Barratt A. Prophylactic antibiotic use in transurethral prostatic resection: a meta-analysis. J Urol 2002;167:571-7.

25. Qiang W, Jianchen W, MacDonald R, Monga M, Wilt TJ. Antibiotic prophylaxis for transurethral prostatic resection in men with preoperative urine containing less than 100,000 bacteria per ml: a systematic review. J Urol 2005;173:1175-81.

26. Yokoyama M, Fujii Y, Yoshida S, Saito K, Koga F, Masuda H, et al. Discarding antimicrobial prophylaxis for transurethral resection of bladder tumor: a feasibility study. Int J Urol 2009;16:613.

27. Janknegt RA. Prophylaxis in urological surgery. Infection. 1992;20 Suppl 3:S213-6; discussion S217-20, S224.

28. Westenfelder M, Rosset K, Pelz K. Development of nosocomial and iatrogenic urinary tract infections (UTI) following urolo- 
gical interventions. A prospective clinical study. Scand J Urol Nephrol Suppl 1987;104:59-63.

29. Bootsma AM, Laguna Pes MP, Geerlings SE, Goossens A. Antibiotic prophylaxis in urologic procedures: a systematic review. Eur Urol 2008;54:1270-86.

30. Delavierre D, Huiban B, Fournier G, Le Gall G, Tande D, Mangin P. [The value of antibiotic prophylaxis in transurethral resection of bladder tumors. Apropos of 61 cases]. Prog Urol 1993;3: 577-82. French.

31. MacDermott JP, Ewing RE, Somerville JF, Gray BK. Cephradine prophylaxis in transurethral procedures for carcinoma of the bladder. Br J Urol 1988;62:136-9.

32. Appell RA, Flynn JT, Paris AM, Blandy JP. Occult bacterial colonization of bladder tumors. J Urol 1980;124:345-6.

33. Chung DY, Cho KS, Lee DH, Han JH, Kang DH, Jung HD, et al. Impact of colic pain as a significant factor for predicting the stone free rate of one-session shock wave lithotripsy for treating ureter stones: a Bayesian logistic regression model analysis. PLoS One 2015;10:e0123800.

34. Lu $\mathrm{Y}$, Tianyong F, Ping $\mathrm{H}$, Liangren $\mathrm{L}$, Haichao $\mathrm{Y}$, Qiang W. Antibiotic prophylaxis for shock wave lithotripsy in patients with sterile urine before treatment may be unnecessary: a systematic review and meta-analysis. J Urol 2012;188:441-8.

35. Hsieh CH, Yang SS, Chang SJ. The effectiveness of prophylactic antibiotics with oral levofloxacin against post-shock wave lithotripsy infectious complications: a randomized controlled trial. Surg Infect (Larchmt) 2016;17:346-51.

36. Fujita K, Mizuno T, Ushiyama T, Suzuki K, Hadano S, Satoh S, et al. Complicating risk factors for pyelonephritis after extracorporeal shock wave lithotripsy. Int J Urol 2000;7:224-30.

37. Shigeta M, Yamasaki A, Hayashi M. [A clinical study on upper urinary tract calculi treated with extracorporeal shock wave lithotripsy (ESWL) monotherapy, with regard to bacteriuria before ESWL treatment]. Jpn J Urol 1993;84:866-72. Japanese.
38. Dincel C, Ozdiler E, Ozenci H, Tazici N, Kosar A. Incidence of urinary tract infection in patients without bacteriuria undergoing SWL: comparison of stone types. J Endourol 1998;12:13.

39. Honey RJ, Ordon M, Ghiculete D, Wiesenthal JD, Kodama R, Pace KT. A prospective study examining the incidence of bacteriuria and urinary tract infection after shock wave lithotripsy with targeted antibiotic prophylaxis. J Urol 2013;189: 2112-7.

40. Fourcade RO. Antibiotic prophylaxis with cefotaxime in endoscopic extraction of upper urinary tract stones: a randomized study. The cefotaxime cooperative group. J Antimicrob Chemother 1990;26 Suppl A:77-83.

41. Lo CW, Yang SS, Hsieh $\mathrm{CH}$, Chang SJ. Effectiveness of prophylactic antibiotics against post-ureteroscopic lithotripsy infections: systematic review and meta-analysis. Surg Infect (Larchmt) 2015;16:415-20.

42. Mariappan P, Smith G, Bariol SV, Moussa SA, Tolley DA. Stone and pelvic urine culture and sensitivity are better than bladder urine as predictors of urosepsis following percutaneous nephrolithotomy: a prospective clinical study. J Urol 2005;173: 1610-4.

43. Kang SK, Cho KS, Kang DH, Jung HD, Kwon JK, Lee JY. Systematic review and meta-analysis to compare success rates of retrograde intrarenal surgery versus percutaneous nephrolithotomy for renal stones $>2 \mathrm{~cm}$ : an update. Medicine (Baltimore) 2017;96:e9119.

44. Seyrek M, Binbay M, Yuruk E, Akman T, Aslan R, Yazici O, et al. Perioperative prophylaxis for percutaneous nephrolithotomy: randomized study concerning the drug and dosage. J Endourol 2012;26:1431-6.

45. Tuzel E, Aktepe OC, Akdogan B. Prospective comparative study of two protocols of antibiotic prophylaxis in percutaneous nephrolithotomy. J Endourol 2013;27:172-6. 